\title{
Reflexões sobre o uso do jornal como fonte para a história da educação piauiense
}

\author{
Reflections on the use of the newspaper as a source for the history of piauiense
}

education

\author{
JANE BEZERRA DE SOUSA (iDa
}

\begin{abstract}
RESUMO
Esse trabalho tem como objetivo mostrar as principais pesquisas desenvolvidas por sua autora na área de história da educação piauiense, tendo como fonte o jornal impresso. $\mathrm{O}$ recorte temporal adotado foi de 1952 a 1971, o início justifica-se pela primeira edição do jornal flâmula e o término pela implantação da lei 5692/71 que alterou significativamente as instituições escolares, tema principal de uma das pesquisas abordadas no texto. Foram analisadas três pesquisas a partir do uso do jornal como fonte. A primeira foi sobre o Jornal Flâmula. A segunda retratou um estudo sobre 15 textos memorialísticos da professora Nevinha Santos, os quais foram publicados no jornal Meio Norte. Por último, o trabalho Educação e imprensa: instituições escolares no Piauí de 1961 a 1971, em que foram consultadas 65 notícias dos jornais. Todos os trabalhos estão imersos na perspectiva da história cultural ou história nova. Como autores que embasam as análises, citamos: Capelato (1988), Luca (2015), Nóvoa (2007), Carvalho (2007) e Le Goff (1984). Essa pesquisa é significativa por revisitar a história da educação piauiense a partir dos jornais; incentivar a utilização do jornal como fonte de pesquisa para a história da educação; impulsionar a investigação do jornal como espaço de memória coletiva; estimular as escolas da atualidade a ocupar novamente os espaços das páginas dos noticiosos e, assim, fecunde a participação da sociedade na educação e reacendendo a luta e resistência por melhores condições de trabalho docente nas instituições escolares.

Palavras-chave: História da educação; Imprensa; Memória
\end{abstract}

\begin{abstract}
This work aims to show the main researches developed by its author in the area of history of education in Piauí, using the printed newspaper as a source. The time frame adopted was from 1952 to 1971, the beginning is justified by the first edition of the newspaper pennant and the end by the implementation of law 5692/71 that significantly altered school institutions, the main theme of one of the researches covered in the text. Three studies were analyzed using the newspaper as a source. The first was about Jornal Flâmula. The second portrayed a study of 15 memorial texts by Professor Nevinha Santos, which were published in the newspaper Meio Norte. Finally, the work Education and the press: school institutions in Piauí from 1961 to 1971, in which 65 news reports were consulted. All works are immersed in the perspective of cultural history or new history.

a Universidade Federal do Piaú (UFPI), PI, Brasil. Doutora em Educação, e-mail: jane_bezerrasousa@yahoo.com.br Orcid: https://orcid.org/0000-0002-4512-7027

Rev. Caminhos da Educação: diálogos, culturas e diversidades, Teresina, v. 1, n. 3, p. 132-148, set./dez. 2019
\end{abstract}


As authors that support the analyzes, we mention: Capelato (1988), Luca (2015), Nóvoa (2007), Carvalho (2007) and Le Goff (1984). This research is significant because it revisits the history of education in Piauí from the newspapers; encourage the use of the newspaper as a research source for the history of education; boost the investigation of the newspaper as a space for collective memory; to stimulate the schools of today to occupy again the spaces of the pages of the news and, thus, to fertilize the participation of the society in the education and to rekindle the fight and resistance for better conditions of teaching work in the school institutions.

Key Words: History of education; Press; Memory

\section{RESUMEN}

Este trabajo tiene como objetivo mostrar las principales investigaciones desarrolladas por su autor en el área de la historia de la educación en Piauí, utilizando el periódico impreso como fuente. El período de tiempo adoptado fue de 1952 a 1971, el comienzo está justificado por la primera edición del banderín del periódico y el final por la implementación de la ley 5692/71 que alteró significativamente las instituciones escolares, el tema principal de una de las investigaciones cubiertas en el texto. Se analizaron tres estudios utilizando el periódico como fuente. El primero fue sobre Jornal Flâmula. El segundo retrató un estudio de 15 textos conmemorativos del profesor Nevinha Santos, que fueron publicados en el periódico Meio Norte. Finalmente, el trabajo Educación y prensa: instituciones escolares en Piauí de 1961 a 1971, en las que se consultaron 65 reportajes. Todas las obras están inmersas en la perspectiva de la historia cultural o la nueva historia. Como autores que respaldan los análisis, mencionamos: Capelato (1988), Luca (2015), Nóvoa (2007), Carvalho (2007) y Le Goff (1984). Esta investigación es significativa porque revisa la historia de la educación en Piauí de los periódicos; alentar el uso del periódico como fuente de investigación para la historia de la educación; impulsar la investigación del periódico como un espacio para la memoria colectiva; estimular a las escuelas de hoy para que vuelvan a ocupar los espacios de las páginas de noticias $\mathrm{y}$, de este modo, fertilizar la participación de la sociedad en la educación y reavivar la lucha y la resistencia por mejores condiciones de trabajo docente en las instituciones escolares.

Palabras Clave: Historia de la educación; Prensa; Memoria

\section{INTRODUÇ̃̃̃O}

Esse trabalho tem como objetivo mostrar as principais pesquisas desenvolvidas por sua autora na área de história da educação piauiense, tendo como fonte o jornal impresso: análise do Jornal Flâmula, criado pelos alunos do Ginásio Estadual Picoense, estudo que fez parte da dissertação de mestrado em educação, realizado na Universidade Federal do Piauí, em 2005; o exame de 15 textos memorialísticos da professora Nevinha Santos, os quais foram publicados no jornal Meio Norte e serviram de fonte para a tese de doutorado, intitulada Ser e fazer-se professora no Piaui, no século XX: a história de 
vida da professora Nevinha Santos, defendida em 2009; por último, o trabalho Educação e imprensa: instituições escolares no Piauí de 1961 a 1971, onde foram consultadas 65 notícias dos jornais O Dia, Estado do Piauí, Jornal do Comércio, Folha da Manhã, A Hora, Opinião e Jornal do Piauí, disponibilizadas pelo Arquivo Público Casa Anísio Brito, e que foram imprescindíveis para o relatório de investigação de pós-doutorado na Universidade Federal de Uberlândia, no ano de 2016. Todos os trabalhos estão imersos na perspectiva da história cultural ou história nova, que possibilitou a historiografia, a ampliação de fontes, temas e objetos.

\section{IMPRENSA E HISTÓRIA DA EDUCAÇÃO}

De início, faz-se necessário apresentar um pequeno esboço sobre a relação entre imprensa e história da educação, indicando teorias, objetos e metodologias, resultados de estudos realizados em meu pós-doutorado, em 2016. Para Capelato (1988), é fascinante aprender a história do Brasil por meio de jornais, uma vez que nos deparamos com aspectos significativos da vida de nossos antecessores, revisitando suas lutas e seus interesses. Nesse âmbito, a imprensa permite acompanhar a experiência humana com o passar do tempo. Antes considerada uma fonte suspeita, atualmente é valiosa para o conhecimento de uma época, fato verificado, principalmente, a partir dos anos 1960, com o advento da corrente historiográfica da história nova ou história cultural, oportunidade em que foram ampliados os objetos, os temas e as fontes da história da educação.

\footnotetext{
A imprensa registra, comenta e participa da história. Através dela se trava uma constante batalha pela conquista dos corações e mentes- essa expressão de Clovis Rossi define bem a atividade jornalística. Compete ao historiador reconstituir os lances e peripécias dessa batalha cotidiana na qual se envolvem múltiplas personagens (CAPELATO, 1988, p. 13).
}

A análise do jornal exige do historiador um constante diálogo com a fonte. $\mathrm{O}$ historiador de hoje reconhece que os fatos foram fabricados, mas mais importante do que isso é a maneira como as pessoas tomaram consciência dos acontecimentos. Logo, é impossível ser completamente objetivo, mas se deve utilizar uma objetividade relativa, uma vez que a subjetividade e os interesses de quem produz o jornal estão presentes nele. Portanto, o historiador deve levar isso em conta (CAPELATO, 1988).

Pesquisar a história por intermédio do jornal é fascinante e pressupõe um trabalho rigoroso, tratando adequadamente a fonte. A historiografia tradicional positivista exige 
do historiador uma crítica rigorosa ao documento. A história nova também requer essa postura, mas não é escrava dela, pois não há um documento-verdade - os Annales recomendavam que não se permanecesse passivo diante das fontes.

Nessa perspectiva, todos os documentos são, ao mesmo tempo, falsos e verdadeiros. A tarefa do historiador consiste em desmistificar o seu significado aparente, explicitando que sua roupagem resulta de uma construção. Demoli-la implica analisar condições em que o documento foi produzido (CAPELATO, 1988, p. 24).

Por isso, o historiador deve fazer perguntas à fonte: quem produziu o jornal? Para que? Como? Quando? Desse modo, cumprirá o papel de analisar seu instrumento de trabalho, que não deve ser estudado isoladamente, mas com outras fontes que aumentem a compreensão sobre o que está sendo pesquisado. O historiador de antes trabalhava dentro das certezas, mas agora reconhece a relatividade da ciência, já que em busca da verdade se encontram muitas outras realidades.

Assim, considerando a questão da subjetividade no reconhecimento da relatividade da ciência em busca dessas verdades, ao trabalhar o jornal como fonte de pesquisa para história da educação, consultei vários livros em busca de uma metodologia e encontrei em Luca (2015) algumas questões práticas, estabelecidas como pontos a serem apreciados, uma vez que sugerir um procedimento metodológico é difícil para dar conta de tantas possibilidades. Como exemplos desses aspectos, podem-se apontar:

Encontrar as fontes e constituir uma longa e representativa série;localizar a(s) publicação (ões) na história da imprensa; atentar para as características de ordem material (periodicidade, impressão; papel, uso/ausência de iconografia e de publicidade); assenhorar-se da forma de organização interna do conteúdo; caracterizar o material iconográfico presente, atentando para as opções estéticas e funções cumpridas por ele na publicação; identificar os principais colaboradores; identificar o público a que se destinava; identificar as fontes de receita; analisar todo o material, de acordo com a problemática escolhida (LUCA, 2015, p. 142).

Os estudos sobre história da educação na imprensa nos levam a examinar os testemunhos de uma época e de que forma a sociedade percebia a educação em determinado período. Nesse sentido, concordamos com a citação abaixo, que mostra ser essa uma tarefa inovadora, que exige dos pesquisadores análises criteriosas, evitando Rev. Caminhos da Educação: diálogos, culturas e diversidades, Teresina, v. 1, n. 3, p. 132-148, set./dez. 2019 
armadilhas dos discursos implícitos de interesses de grupos que tinham acesso e controle sobre os meios de comunicação.

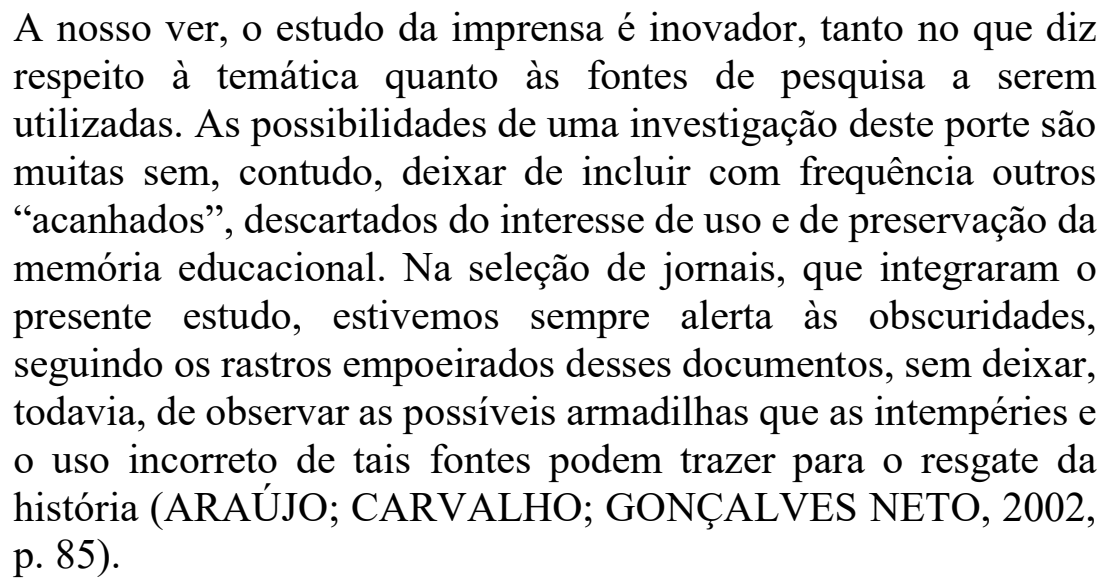

A imprensa, como representação de diversos atores, configura uma de suas melhores qualidades como fonte de pesquisa, por constituir uma imensa diversidade. Além disso, cada voz está sempre a ser analisada ou julgada pelos leitores, como em um sistema regulador. Então, corroboramos com essa ideia baseado no fato de que "a imprensa é o lugar de uma firmação em grupo e de uma permanente regulação coletiva, na medida em que cada criador está sempre a ser julgado pelo público, seja por outras revistas, seja pelos seus próprios companheiros de geração" (NÓVOA, 2002, p. 13). Dessa forma, a imprensa é uma linguagem que modela ou inspira formas de pensar e agir.

A imprensa retrata a voz de uma comunidade e de um grupo, mostra como as pessoas pensavam, discutiam, viviam em determinada época, daí porque representa um espaço rico para pesquisa em história da educação, por desvelar essas múltiplas vozes.

Seguem abaixo três momentos em que trabalhei com o jornal como fonte de pesquisa, proposta que se faz na organização desse livro. A primeira experiência trata-se de um estudo sobre o jornal Flâmula, que muito contribuiu para minha dissertação, defendida no ano de 2005. Parte desse texto foi publicado no trabalho Picos e a consolidação de sua rede escolar (1929 a 1949).

\section{FLÂMULA: DE PEQUENA CHAMA A RÚTILO CLARÃO}

Essas análises partiram da pesquisa realizada no ano de 2005, intitulada: Picos e a consolidação de sua rede escolar. O jornal Flâmula surgiu com apoio incondicional do professor Vidal de Freitas, juiz de direito da cidade de Picos (PI) e diretor do Ginásio 
Estadual Picoense, fundado em 1949, tendo sido um dos seus idealizadores. A primeira edição do referido jornal saiu no dia 15 de março de 1952. No mesmo dia, foi inaugurada a gráfica ginasial, em uma cerimônia religiosa presidida pelo Padre José Inácio Madeira, com animação da Banda Municipal e tendo como oradores o professor Acelino Leite, o Dr. Antenor Neiva e José Albano de Macedo (Ozildo), que assim se manifestou:

Uma falange de jovens aspirantes de grandes ideais concretiza hoje o seu sonho fagueiro de ontem. Pugnando por essa justa causa, não poupamos esforços nem medimos sacrifícios. Não houve obstáculos que não fossem vencidos, nem dificuldades que nos abatessem. Hoje, apresentamos o fruto dos nossos labores "Flâmula", o jornal que irá engrandecer e dar nova vida a Picos. Flâmula, ou pequena chama, em breve tornar-se-á um rútilo clarão, não como o fogo fátuo que brilha por um instante, depois se apaga, mas como uma estrela cintilante que brilhará para aqueles que têm sede de saber, do dever e do amor à Pátria.

O 15 de março é um marco na história literária, social e progressista de Picos, pois neste dia sai o primeiro jornal que irá descortinar à mocidade estudiosa de nossa terra novos horizontes no campo das letras.

Picos, cidade nova que marcha alteinaramente para o progresso, há muito precisava de um emissário que levasse a longe sua grandeza, o labor de seu povo e a inteligência de seus filhos. Esse emissário, esse porta-voz é a Flâmula, que contará o nosso passado, enaltecerá as grandezas do presente e idealizará um por vir risonho para a terra que nos serviu de berço.

Todo cidadão conspícuo e nobre, honrado e patriota, deverá ajudar e colaborar com os estudantes nesse grande empreendimento.

Sentimo-nos hoje orgulhosos por termos trabalhado denotadamente, lutando com ardor nessa campanha. Estamos satisfeitíssimos, apesar dos sacrifícios que fizemos, das canseiras e dos trabalhos que tivemos, das humilhações e dos afrontamentos que recebemos, pois diz Corneille em dos seus versos - “Ã vaincre sans péril, on riomphe sans gloire (Quando se vence sem perigo, triunfa-se sem glória).” (ALBANO, 1952a, p. 3).

O jornal Flâmula teve catorze edições, sendo que a última circulou no dia 18 de janeiro de 1953. Nesse intervalo de tempo, entre a fundação e sua última edição, ele representou mais que um jornal, fato previsto pelo estudante Ozildo Albano, em seu pronunciamento quando da inauguração da gráfica ginasial. Foi um noticioso idealizado por jovens ginasianos, conscienciosos da importância que tal ato tinha não somente na vida da escola de que participavam, mas também da sociedade em que viviam. 
Naquela oportunidade, Ozildo Albano fez um inflamado discurso, afirmando que o nome do jornal significava uma pequena chama e que se tornaria um rútilo clarão. Considerando as influências e a circulação de um ano e dois meses desses escritos na cidade e, ainda, o pensamento e a produção escrita de tantos jovens aspirantes de um ensino ginasial e superior, esse jornal tornou-se um marco importante na história da formação da juventude da época.

Era constituído por artigos de alunos, professores e inspetores. Expressões francesas como "le monde marche", "laissez faire" eram constantes, frutos do currículo que continha a disciplina de francês e do status desta naquele momento. Era lido em outras localidades - provam isso as correspondências recebidas de Codó (MA), Oeiras, entre outros municípios. A presença de uma coluna assinada por Otílio Neiva Coelho, intitulada Recado do Recife, atestava o rompimento da leitura além da esfera local. Havia também uma seção charadística e a coluna social que informava a visita de outros ginasianos, como os de Oeiras e de Valença do Piauí. Ademais, eram inseridos anúncios e editais, assim como o balanço contábil da Prefeitura.

Inicialmente, esse veículo de comunicação foi criado com o objetivo de divulgar artigos literários e fatos relacionados à educação, a fim de despertar nos estudantes o interesse pela leitura e pela produção literária. No entanto, pela falta de recursos para manutenção e impressão do jornal, havia participação intensa dos poderes Judiciário e Executivo, comprovada devido à constante publicação de editais e balancetes - tanto é que em pouco tempo, o jornal deixou de circular por impossibilidade de financiar sua confecção.

Flâmula destacou-se por não ser um jornal oficial da Prefeitura, nem do Estado, tampouco de empresários da época, mas dos estudantes ginasianos. O estímulo e a alegria do momento evidenciavam-se nos escritos de professores, alunos e membros da comunidade.

[...] que nos moços sejam apontados os rumos por onde trilhavam os luminares da sabedoria e que se lhes faça acordar na alma a sensibilidade para o sonho e para a grandeza. Feito isto, teremos transformado aquela fonte de esperanças apagadas em caudal imenso de realidades palpitantes (LEITE, 1952, p. 1).

O estudante Alfredo Albano, em seu primeiro artigo publicado no jornal, intitulou o momento de despertar da mocidade. Teles $(1952$, p. 2) prefere assim caracterizá-lo: 
sonho não, realidade. Marques Filho (1952, p. 2), membro da comunidade, enalteceu-o com o seu comentário: "foram os jovens que sem ouvirem falsos profetas", engrandecendo a independência e a autonomia do jornal em relação aos cofres públicos. Portanto, o jornal configurou-se como o esforço arrojado dos jovens, o que significava, de certa forma, uma importante ação para a sociedade picoense.

Dos alunos responsáveis pela sua existência, dois tiveram papel importante: Alfredo Albano e Ozildo Albano. O primeiro escrevia sobre diversos assuntos, como os retirantes, opinando sobre a seca do Nordeste, utilizando citações de Euclides da Cunha e Olavo Bilac, em uma clara demonstração de que para escreverem os artigos, havia leitura prévia de uma bibliografia selecionada. A do sertão era sua predileta. $\mathrm{Na} 12^{\mathrm{a}}$ edição, publicou Paisagens do sertão, que descrevia, de forma romântica e saudosista, a paisagem dos morros de Picos: "Picos, serras e chapadas, todos vestidos de verde como palhaços em dia de exibição.” (ALBANO, 1952b, p. 3). O último de seus escritos, publicado na $14^{\mathrm{a}}$ edição, intitulado Vida estudantil, expressava as brigas internas do grêmio e da gráfica ginasial, o que podemos entender como os últimos suspiros do jornal que se tornava um "fogo fátuo", justamente o que os idealizadores não desejavam. As intrigas internas ficaram notórias quando afirmou "a verdade não se cansa porque é eterna" (ALBANO, 1953, p. 4).

Por sua vez, Ozildo Albano concentrava a produção de seus textos em datas festivas. Seu assunto preferido eram os relacionados à Revolução Francesa. A exemplo de outros Ginásios do período, que fundaram jornais e grêmios, os temas preferidos voltavam-se para esse movimento histórico. Os artigos de Ozildo foram 13 de maio, assinalando a comemoração da Lei Áurea e vangloriando a Princesa Isabel; Castro Alves, narrando as mazelas vividas pelos escravos no Brasil, e concluindo que aqui não havia mais preconceito de cor e raça; Batalha de Riachuelo, que notabilizava a data de realização de uma das batalhas da Guerra do Paraguai; Batalha de Waterloo, texto em comemoração à data de 18 de junho de 1815, que descrevia a derrota de Napoleão Bonaparte e considerava suas atitudes como resistência heroica. Escreveu, ainda, $A$ queda da bastilha, exaltando a Revolução Francesa; e Paz e Liberdade, que tratava do Tratado de Versalhes. Seus escritos eram descritivos, salientando as grandes datas, os grandes feitos e os grandes heróis. Eram escritos informativos sobre fatos e personagens da história, oferecendo a quem os lesse uma compreensão fácil do que era abordado.

Os ginasianos concebiam o magistério como um sacerdócio, uma escolha vocacional e um compromisso com a sociedade. No editorial intitulado Magistério e Rev. Caminhos da Educação: diálogos, culturas e diversidades, Teresina, v. 1, n. 3, p. 132-148, set./dez. 2019 
Sacerdócio, da edição $\mathrm{n}^{\circ}$ 03, escreveram: “O magistério é um verdadeiro sacerdócio. Verdadeiro naquele elevado sentido em que foi o divino Jesus" (MAGISTÉRIO...,1952, p. 1).

Abordaram, ainda, nesse mesmo editorial, que o professor deve receber o salário, mas perceber a profissão como patriótica e um dever com os pais dos alunos, pois o magistério só é digno de nome se for exercido com abnegação e esforço sacrificial. A ideia de trabalho ligado a outras profissões era reforçada pelos alunos como desenvolvimento e progresso da nação. A aluna Lourdinha Santos, na edição $n^{0}$ 05, definiu que "O trabalho é a coisa mais sublime que a natureza criou [...] como é linda uma pátria em que seu povo visa ao seu desenvolvimento. Como é que se visa ao progresso de uma nação? Trabalhando, estudando e progredindo" (SANTOS, 1952, p. 1).

Os editores do Flâmula acompanhavam as discussões e mudanças em relação ao ensino nacional. No editorial da edição $\mathrm{n}^{0}$ 6, comentaram a respeito de uma reunião ocorrida em São Paulo com reitores das universidades, ocasião em que foi proposta a instituição de um ano no primário; a idade mínima de doze anos para o exame de admissão; o segundo ciclo do ensino secundário com apenas duas séries; e colégio universitário com duração de um ano, com aulas ministradas na escola superior a que se destinasse o aluno. A esse respeito, os discentes opinaram que se tal reforma fosse votada, seria uma forma de minimizar a deficiência do ensino primário, que formava alunos com baixo poder intelectual: "A criação de mais um ano de primário concorrerá para que não mais se vejam, nas primeiras séries ginasiais, alunos de nível intelectual inferior ao do mais propedêutico dos cursos" (ENSINO..., 1952, p. 1).

Os temas escritos no jornal Flâmula refletiam o ensino que era ministrado para esses alunos, permeado de ideais e construção de valores como obediência e respeito ao mestre; comportamento moral; valorização dos grandes feitos da história; reconhecimento do papel da mulher; e trabalho como algo dignificante. 
Figura 1 - Jornal Flâmula

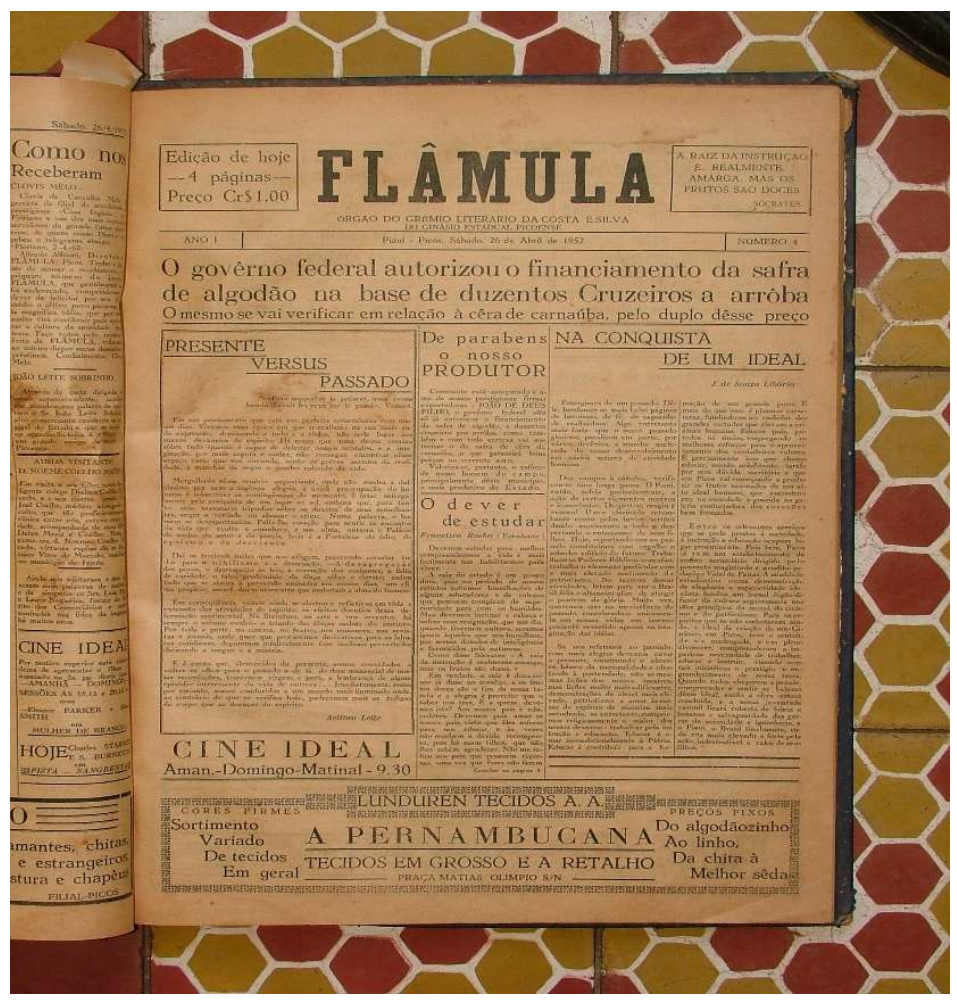

Fonte: Museu Ozildo Albano

No ano de 2009, defendi minha tese de doutoramento, a qual tratava de um estudo em história da educação, cujo objetivo era investigar o ser e o fazer-se professora no Piauí, no século XX, por meio da história de vida da professora normalista Nevinha Santos, que escreveu suas memórias em caderno de anotações e as publicou em forma de artigos no Jornal Meio Norte, de Teresina-PI.

São quinze textos que abordam temas ligados à educação, à política e à escrita de si mesma. Outras fontes foram utilizadas e cruzadas com os textos publicados no jornal, como entrevistas de ex-alunos, familiares e contemporâneos, bem como mensagens governamentais, com o intuito de conhecer as possibilidades históricas, sociais e culturais que permitiram conceber o sentido da função de ser professor no Piauí do século XX, compreendendo, especificamente, sua história de vida, enfocando o seu fazer-se professora, o ser professora primária e as condições histórico-sociais que permitiram constituí-la de tal modo.

Os textos são de autoria da professora normalista Nevinha Santos e dois referentes à sua história, escritos por jornalistas do Estado, publicados no Jornal Meio Norte, sempre com ilustrações ligadas ao escrito, de autoria de Moisés dos Martírios. O seu filho, Luís Rev. Caminhos da Educação: diálogos, culturas e diversidades, Teresina, v. 1, n. 3, p. 132-148, set./dez. 2019 
Ayrton Santos, levou seus textos àquele jornal, oportunidade em que ela ganhou uma coluna no caderno alternativo. Este não publicava matérias gerais, mas se destinava ao público selecionado, como: estudantes, acadêmicos, pesquisadores, pessoas que gostam de cultura, arte e literatura. Seus artigos eram mensais.

Passaremos a apreciar a descrição de parte de seus textos, cuja totalidade pode ser lida e analisada no livro Ser e fazer-se professora no Piauí no século XX: a história de vida de Nevinha Santos, publicado pela EDUFU no ano de 2015, bem como na tese de mesmo título, defendida no ano de 2009, na Universidade Federal de Uberlândia. Todos os textos foram igualmente publicados em um livro de autoria de seu filho, Luiz Ayrton Santos, intitulado Professora Nevinha Santos.

O primeiro texto, A Decadência do Estado Novo, foi publicado em 22 de setembro de 1997. Nele, a professora declarou que resolveu escrever, mas não sabe o porquê de lembrar-se de fatos ocorridos há cinquenta anos. Descreve como foi a queda do Estado Novo na cidade de Picos (PI), momento histórico em que o marido era prefeito e ela, primeira-dama.

Foi o fim do Estado Novo e naquele dia muita gente da cidade de Picos que odiava o presidente Vargas e odiava mais ainda as pessoas que estavam no poder naquela comunidade é que galgaram posições políticas, cargos importantes e que detinham o poder de mando em suas mãos. Até hoje sentimos a inveja, o ódio e o despeito de alguns. Isso passou de pais para filhos e de filhos para netos. Nunca perdoaram uma jovem professora de outro lugar se tornar a primeira-dama de uma cidade importante, mesmo sendo ela piauiense preparada e educada. Naquela cidade onde morei e nasceram todos os meus filhos e que adotei como minha por toda vida, por diversas vezes assisti cenas deprimentes (SANTOS, 1997a, p. 3).

O segundo texto, nomeado Adorei e me sentia muito feliz em ser professora, publicado no dia 22 de outubro de 1997, conta toda a história da chegada de professoras normalistas à cidade de Picos (PI). O artigo Lembrando Marruás e minha cidade natal, divulgado em 18 de dezembro de 1997, é um texto autorreferencial que mostra o início da escrita sobre si mesma.

Em 1997, a professora Nevinha perdeu sua nora, Maria Carvalho Santos, que faleceu vítima de um câncer de mama, a quem dedicou um texto chamado Lembranças 
de Maria, onde manifestou saudade da nora e contou a trajetória de vida desta junto ao marido, Ayrton.

Em Saudades de uma infância em contato com a natureza, de 22 de janeiro de 1998, Nevinha relembrava o sítio Campos do Meio, em Picos (PI), e a infância de seus filhos: "Depois do jantar, todas as crianças ficavam no alpendre ouvindo histórias de lobisomem, príncipes e princesas encantadas, e bichos do mato que a mulher do morador contava para eles" (SANTOS, 1998a, p. 3).

Teresina é o foco principal do texto A beleza e a simplicidade de uma Teresina antiga, onde Nevinha faz uma descrição de praças, ruas, pessoas, bares, cinemas de uma Teresina do início do século, com características minuciosas do cenário onde morou e viveu nos anos de formação como professora normalista.

Os outros textos estão voltados para a cidade Picos, com a evocação do coronel Francisco Santos, por quem tinha muita admiração, pois além de sogro, foi um dos responsáveis pela fundação do Grupo Escolar. Um certo Coronel Francisco Santos, Uma volta ao Passado e A última viagem que fiz à minha terra são textos descritivos de sua vida em Picos, retratando a cidade, o Grupo, seus alunos, suas companheiras de magistério, as pessoas que conheceu por lá e os reencontros com habitantes da cidade.

Vida, um quadro permanente foi seu último texto publicado. Nele, a emoção sobressai-se, configurando-se como texto autorreferencial. ${ }^{1}$ Nesse escrito, Nevinha traz à tona o que estava no recôndito de si: as mágoas, as dores, as alegrias, os bons momentos, as boas amizades, as noites de luar e a recepção aos amigos. Ela terminou sua escrita afirmando: "assim é a vida. Cheia de amarguras e decepções, mas também repleta de momentos inesquecíveis" (SANTOS, 1999, p.03).

Em entrevista ao Jornal Meio Norte, sobre o movimento docente e as greves ocorridas no ano de 1997, ela declarou: “Os salários são atrasados e não são suficientes para o profissional da educação manter a família. Portanto, os movimentos grevistas devem reivindicar melhores salários e condições de trabalho.” Reclamou, ainda, de seu salário de $\mathrm{R} \$ 225,00$ (duzentos e vinte e cinco reais), em 1997, e lembrou: "Na minha época, o professor era respeitado pela sociedade e pelo governo, que pagava bem e não deixava atrasar salários.”

\footnotetext{
${ }^{1}$ São textos que representam a escrita de si. O termo surgiu da relação do indivíduo moderno com seus documentos, mesmo considerando que essa prática já ocorria desde a Idade Média e, mais deliberadamente, a partir do século XVIII, quando indivíduos comuns passaram a produzir suas memórias. Esses textos têm possibilitado várias pesquisas e diferentes resultados na forma de os historiadores lidarem com essas novas fontes.

Rev. Caminhos da Educação: diálogos, culturas e diversidades, Teresina, v. 1, n. 3, p. 132-148, set./dez. 2019
} 
Todos esses textos, publicados no Jornal Meio Norte, serviram de aporte para a minha tese de doutorado, bem como para outros trabalhos publicados e que contribuem para a memória coletiva da educação do nosso Estado, além de refletirem sobre aspectos da vida da referida professora. Destarte, mostra fatos políticos e culturais de uma época. O registro nos jornais nos possibilitou conhecer esse período histórico e lançar reflexões sobre a profissão docente, as histórias de vidas de professores, entre outras temáticas.

\section{O DIA, ESTADO DO PIAUÍ, JORNAL DO COMÉRCIO, FOLHA DA MANHÃ, A HORA, OPINIÃO E JORNAL DO PIAUÍ (1961-1971)}

Educação e imprensa: instituições escolares no Piauí (1961-1971) fez parte de minha investigação no pós-doutorado, na Universidade Federal de Uberlândia, realizado durante o ano de 2016. O recorte temporal teve como base inicial o ano de 1961, a partir da implantação da lei 4024/61, e como final, a implementação da lei 5692/71. A promulgação de ambas proporcionou mudanças na sistematização e organização da educação, afetando substancialmente a criação e o funcionamento de instituições escolares piauienses.

Os objetivos do estudo foram: analisar os discursos, as mensagens, as fotografias, os anúncios e os editorias sobre instituições escolares no Piauí, de 1961 a 1971, presentes nos jornais do Arquivo Público do Estado do Piauí; e verificar as mensagens produzidas pela imprensa piauiense sobre as instituições escolares no Piauí. Utilizaram-se como fontes os jornais que estão à disposição para consulta no Arquivo Público do Estado do Piauí, Casa Anísio Brito, referentes ao período de 1961 a 1971- são eles: O Dia, Estado do Piauí, Jornal do Comércio, Folha da Manhã, A Hora, Opinião e Jornal do Piauí.

Dessa forma, foram verificados notícias, mensagens e discursos que envolvem as instituições escolares no Piauí, no período analisado. A pesquisa caracterizou-se como histórica, bibliográfica e documental. Foram coletadas 65 (sessenta e cinco) notícias de jornais, analisadas e agrupadas em categorias inspiradas nos trabalhos de Buffa e Nosella (2005), a saber: contexto histórico, evolução, edifício escolar, alunos, saberes, professores e administradores, normas disciplinares e eventos.

A pesquisa sobre instituições escolares no Piauí, divulgadas nas notícias de jornais, fundamentou-se na história cultural, uma vez que por meio dessa corrente historiográfica, é possível ampliar a noção de fonte e de objetos de estudos para a 
compreensão da experiência humana tendo o tempo como ponto de partida, corroborando com Chartier (2002).

Os estudos de Carvalho, Araújo, Gonçalves Neto (2002), que tem a imprensa como objeto de análise, enriquecem a pesquisa histórica, principalmente na área da educação. Outrossim, Bastos (2002) concebe a imprensa como um testemunho vivo de teorias, métodos, práticas, ideologias e políticas de determinada época.

As categorias estipuladas para o estudo foram: o contexto histórico e as circunstâncias específicas de criação e instalação da escola (16 notícias); seu processo evolutivo - origens, apogeu e situação atual, a vida da escola (25 notícias); o edifício escolar - organização do espaço, estilo, acabamento, implantação, reformas e eventuais descaracterizações (4 notícias); os alunos - origem social, destino profissional e suas organizações (3 notícias); os professores e administradores - origem, formação, atuação e organização (10 notícias); os saberes - currículo, disciplinas, livros didáticos, métodos e instrumentos de ensino (1 notícia); as normas disciplinares - regimentos, organização do poder, burocracia, prêmios e castigos; os eventos- festas, exposições, desfiles e outros (6 notícias). Finalmente, classificaram-se conforme as instituições escolares: Universidade Federal do Piauí, Faculdade de Direito, Faculdade Católica de Filosofia, Faculdade de Odontologia, Escola Normal, Liceu, Ginásio Picoense e escolas vinculadas à SEDUC.

Considerando as categorias de análise, denotou-se uma predominância sobre o item evolução (25 notícias), que abordava, principalmente, o cotidiano da escola, os exames de admissão, os vestibulares, os convites, as matrículas, os editais e as propagandas, com especial atenção para a Faculdade de Odontologia, a Faculdade de Direito, o Colégio Diocesano, o Ginásio Picoense e o Liceu.

Em seguida, destacava-se o contexto histórico (16 notícias), que evidenciava a Faculdade Odontologia, os Grupos Escolares, a Universidade Federal do Piauí, referindose, basicamente, ao processo de implantação das escolas. Em um terceiro patamar, relevavam-se professores e administradores (10 notícias), referindo-se ao professor Bacurau, aos salários atrasados, às denúncias e defesas do reitor da UFPI, Hélcio Ulhoa Saraiva.

Em se tratando de instituições escolares, o protagonismo foi da Universidade Federal do Piauí, com 21 notícias, versando sobre as lutas e resistências empreendidas devido à sua instalação no Estado, os jornais como instrumento divulgador dessa 
contenda e se utilizando de estratégias educativas no sentido de conscientizar a sociedade sobre a importância de instalar uma universidade na região.

Vislumbramos, também, a mobilização realizada pelos alunos no período estudado, seja cobrando melhores condições para as escolas, buscando recursos para excursões ou procurando resolver conflitos de notas com professores, por intermédio dos jornais, configurando-se como pressão ou socialização de resultados pela sociedade piauiense. Vale enfatizar que os leitores de jornais entre 1961 a 1971, em sua maioria, pertenciam à elite ou à classe média do Estado do Piauí.

Os edifícios escolares tiveram em manchete apenas como inaugurações: Grupo Escolar em Caracol e Anísio de Abreu; o Ginásio Municipal Eurípedes Aguiar; e a Escola Normal em Picos.

É oportuno salientar o concurso realizado nas páginas de jornais, referente à disciplina matemática, episódio estimulador para estudantes, além de facultar o aumento nas vendas de periódicos e incentivar participação da comunidade, conclamada a resolver as questões da disciplina.

Verificou-se, inclusive, que o comportamento moral do professor ainda era cobrado, mesmo que de forma anônima, o que nos leva a inferir que bebedeiras, solicitações de favores e gestões mal conduzidas não eram bem vistas socialmente.

Os jornais serviram, similarmente, como espaços de denúncias e luta docente, particularidade patenteada pela notícia de que os professores da Faculdade de Direito cobraram seus salários, ameaçando pedir demissão, sendo prontamente atendidos meses depois.

Os eventos das escolas foram divulgados por meio das semanas universitárias, escolhas de rainhas escolares e formaturas, onde muitas dessas festas eram promovidas no Clube dos Diários, inclusive era uma prática publicar a fotografia de todos os formandos da Faculdade de Direito nos noticiosos.

\section{CONSIDERAÇÕES FINAIS}

Esse trabalho faz uma análise em pesquisas já realizadas por esta pesquisadora que tem o uso do jornal como fonte para pesquisa em história da educação, dessa forma, apontamos inicialmente a pesquisa sobre Educação e Imprensa: as instituições escolares no Piauí (1961 a 1971), em seguida o Jornal Flâmula que foi editado pelos Ginasianos da cidade de Picos e em seguida os textos memorialísticos, publicados no Jornal Meio Norte Rev. Caminhos da Educação: diálogos, culturas e diversidades, Teresina, v. 1, n. 3, p. 132-148, set./dez. 2019 
pela professora Nevinha Santos, essas reflexões realizadas foram significativas por revisitar a história da educação piauiense a partir dos jornais; incentivar a utilização do jornal como fonte de pesquisa para a história da educação; impulsionar a investigação do jornal como espaço de memória coletiva; estimular as escolas da atualidade a ocupar novamente os espaços das páginas dos jornais e, assim, fecunde a participação da sociedade na educação e reacenda a luta e resistência por melhores condições de trabalho docente nas instituições escolares.

\section{REFERÊNCIAS}

ALBANO, Ozildo. Gráfica ginasial. Flâmula, Picos, p. 3, 15 mar. 1952a.

. Passagens do sertão. Flâmula, Picos, p. 3,19 out. 1952b.

. Vida Estudantil. Flâmula, Picos, p. 4, 20 jan. 1953.

AMARAL, Giana Lange do. O gymnasio pelotense e a maçonaria: uma face da história da educação em Pelotas. Pelotas: UFpel, 1999.

BASTOS, Maria Helena Câmara. Espelho de papel: a imprensa e a história da educação. In: ARAÚJO, José Carlos de Souza; GATTI JÚNIOR, Décio (Org.) Novos temas em história da educação brasileira: instituições escolares e educação na imprensa. Campinas, SP: Autores Associados; Uberlândia, MG: EDUFU, 2002. p. 151-174.

CAPELATO, Maria Helena Rolim. Imprensa e história do Brasil. São Paulo: Contexto, 1988.

CARVALHO, Carlos Henrique de; ARAÚJO, José Carlos de; GONÇALVES NETO, Wenceslau. Discutindo a história da educação: a imprensa enquanto objeto de análise histórica (Uberlândia-MG, 193-1950). In: ARAÚJO, José Carlos de Souza; GATTI

JÚNIOR, Décio (Org.) Novos temas em história da educação brasileira: instituições escolares e educação na imprensa. Campinas, SP: Autores Associados; Uberlândia, MG: EDUFU, 2002. p. 67-90.

ENSINO Nacional. Flâmula, Picos, p. 1, 24 mai. 1952.

LEITE, Acilino. O poder do estímulo. Flâmula, Picos, p. 1, 15 mar. 1952.

LUCA, Tania Regina. História da imprensa no Brasil. 2. ed. São Paulo: Contexto, 2015. p. 24-43.

MARQUES FILHO, Antonio. Flâmula, Picos, p. 2, 15 mar. 1952.

MAGISTÉRIO e Sacerdócio. Flâmula, Picos, p. 1, 12 abr. 1952.

Rev. Caminhos da Educação: diálogos, culturas e diversidades, Teresina, v. 1, n. 3, p. 132-148, set./dez. 2019 
NOSELLA, Paolo; BUFFA, Ester. As pesquisas sobre instituições escolares: o método dialético marxista de investigação. Eccos - Revista Científica. São Paulo, v. 7, n. 2, p. 351-68, jul./dez.2005. Disponível em: $<$ http://www.uninove.br $>$. Acesso em:2 jul. 2017.

NÓVOA, Antonio. A imprensa de educação e ensino: concepção e organização do repertório português. In: CATANI, Denice Barbara; BASTOS, Maria Helena Camara. Educação em Revista: a imprensa periódica e a história da educação. São Paulo: Escrituras, 2002. p.11-31.

SANTOS, Lourdinha. O trabalho. Flâmula, Picos, p. 1, 10 mai.1952.

SANTOS, Nevinha. Decadência do Estado Novo. Jornal Meio Norte, Teresina, PI, p. 3, 22 set. 1997a. (Caderno Alternativo).

Saudades de uma infância em contato com a natureza. Jornal Meio Norte, Teresina, PI, n. 1116, 22 jan. 1998. (Caderno Alternativo).

A vida é um quadro permanente. Jornal Meio Norte, Teresina, PI. 1999.

TELES, Rosreimar. Sonho, não. Realidade! Flâmula, Picos, p. 2, 15 mar. 1952.

RECEBIDO: 08/06/2019

APROVADO:03/08/ 2019
RECEIVED: 08/06/2019

APPROVED: 03/08/ 2019
RECIBIDO: 08/06/2019

APROBADO: 03/08/ 2019 